\title{
Effect of carbon nanotubes on friction and wear of a piston ring and cylinder liner system under dry and lubricated conditions
}

\author{
Zhinan ZHANG ${ }^{1,2, *}$, Jun LIU' ${ }^{2}$, Tonghai WU ${ }^{3}$, Youbai XIE ${ }^{1,2}$ \\ ${ }^{1}$ State Key Laboratory of Mechanical System and Vibration, Shanghai Jiao Tong University, Shanghai 200240, China \\ ${ }^{2}$ School of Mechanical Engineering, Shanghai Jiao Tong University, Shanghai 200240, China \\ ${ }^{3}$ Key Laboratory of Education Ministry for Modern Design and Rotor-Bearing System, Xi'an Jiaotong University, Xi'an 710049, China \\ Received: 03 August 2016 / Revised: 24 August 2016 / Accepted: 11 September 2016 \\ (C) The author(s) 2016. This article is published with open access at Springerlink.com
}

\begin{abstract}
This study involves the application of carbon nanotubes (CNTs) to a piston ring and cylinder liner system in order to investigate their effect on friction and wear under dry and lubricated conditions. Carbon nanotubes were used as a solid lubricant and lubricant additive in dry and lubricated conditions, respectively. Simulation and measurement of friction and wear were conducted using a reciprocating tribometer. Surface analysis was performed using a scanning electron microscope and an energy dispersive spectrometer. The results indicate that carbon nanotubes can considerably improve the tribological performance of a piston ring and cylinder liner system under dry sliding conditions, whereas improvement under lubricated conditions is not obvious. Under dry friction, the effective time of the CNTs is limited and the friction coefficient decreases with an increase in CNT content. Furthermore, the dominant wear mechanism during dry friction is adhesive.
\end{abstract}

Keywords: carbon nanotubes; piston ring; tribological behavior; friction; wear

\section{Introduction}

The piston ring and cylinder liner (PRCL) is a key tribosystem in an automotive engine. The friction and wear properties of the PRCL directly relate to automotive engine performance. Meanwhile, the never-ending evolution of energy conservation and emission reduction regulations for automobiles has driven the auto industry to continuously attempt to reduce friction loss in engine components in order to meet such regulations and maintain a competitive edge in the market [1]. The tribological problems regarding the PRCL system remain; however, they must be overcome in order to keep adapting with the development of auto engines [2].

Researchers have developed or improved various motion models to understand the detailed interactions between the piston ring and cylinder liner [3-6]. Numerous methods have been proposed for reducing the friction and wear of the PRCL tribosystem, e.g., surface modification [4, 5], lubrication improvement [6], and mechanical design [7]. Currently, lubricating oil additives have gained considerable research interest [3]. Carbon nanotubes (CNTs) $[8,9]$ have attracted much attention for industrial applications [10-13] owing to their outstanding mechanical properties, e.g., high elastic modulus, high tensile strength, and good thermal conductivity. Although CNTs provide excellent performance, whether they are a viable lubricating oil additive for the PRCL system is still in question.

Some investigations show that CNTs can be used as a reinforcing material in polymer-based composites. For example, Yan et al. [14] investigated the friction and wear properties of pure epoxy resin and aligned carbon nanotube-reinforced epoxy resin composites under water lubricated conditions and found that the latter showed a lower friction coefficient and higher wear rates than pure epoxy resin. Düzcükoğlu et al. [15]

* Corresponding author: Zhinan ZHANG, E-mail: zhinanz@sjtu.edu.cn 
and Cui et al. [16] investigated the tribological behavior of multiwall carbon nanotube (MWCNT)modified epoxy resin under dry sliding conditions and concluded that nanoparticle modification resulted in enhanced wear resistance and reduced friction coefficient and working temperature under dry conditions. LaBarre et al. [17] evaluated the influence of MWCNTs on the impact performance and contributing constituent properties of Kevlar. The results suggested that MWCNT treatment has the potential to improve the ballistic limit of fabrics through increased interfilament and inter-yarn friction without compromising fiber strength or adding significant mass. Gandhi et al. [18] presented the effect of the addition of CNTs to polypropylene on wear performance under dry sliding conditions. They found that an increase in CNT content improved the wear properties of the studied material and an increase in CNT percentage increased the wear resistance. Lee et al. [19] studied the effect of CNT length on the wear of polyamide 6,6 nanocomposites and observed that wear resistance improved with long CNTs and this improvement was more obvious at elevated temperatures.

CNTs can also be used as a reinforcing phase in a metal matrix, because their high strength and toughness help to decrease friction and wear. Al-Qutub et al. [20] studied the friction and wear behavior of an Al6061 monolithic alloy and a $1 \mathrm{wt} \%$ CNT-reinforced Al6061 composite prepared via ball milling and spark plasma sintering. They observed that under mild wear conditions, the composite displayed a lower wear rate and friction coefficient compared with the monolithic alloy. However, under severe wear conditions, the composite displayed a higher wear rate and friction coefficient compared with the monolithic alloy. Bastwros et al. [21] studied the effects of CNT content on the wear behavior of aluminum-carbon nanotube composites. They found that hardness and wear resistance significantly increased with CNT content. The CNTs were either partially or fully crushed, forming a carbon film that covered the surface and acted as a solid lubricant, significantly enhancing the wear behavior. Abdullahi et al. [22] developed a wear map that served as a tool for identifying and displaying regimes of different types of wear for a CNT-Al nanocomposite material, e.g., mild adhesive wear, mixed wear and severe adhesive wear. Khuu et al. [23] investigated the effects of MWCNT content on the adhesive strength, wear, and corrosion resistance of epoxy composite coatings prepared on aluminum alloy 2024-T3 substrates and found that the adhesive strength improved with increasing MWCNT content. In addition, increased MWCNT content decreased the friction coefficient and increased the wear and coating pore resistances.

Furthermore, CNTs can be added to oil to form a stable and homogeneous CNT grease that provides better lubrication performance and wear resistance than oil [24]. To reduce the friction loss in an internal combustion engine, Kałużny et al. [25] conducted engine tests using pistons with carbon nanotubes covering the skirt and demonstrated the resulting advantages. They found that a nanotube layer on the piston skirt contributes to a considerable reduction in friction losses under a wide range of engine operational conditions. In fact, in an internal combustion engine, about $20 \%-30 \%$ of the mechanical power loss is caused by friction loss in the PRCL tribosystem [2]. Therefore, the application of CNTs to a PRCL tribosystem may be beneficial. To the best of our knowledge, limited research has been conducted on this topic.

This study applied CNTs to a PRCL tribosystem and analyzed the tribological performance of the system under different working conditions. In the dry sliding tests, the CNTs acted as a solid lubricant by decreasing friction and wear. In the lubricated tests, the CNTs were used as a lubricant additive to improve lubrication performance. The tests were conducted using a friction abrasion testing machine, and the wear surfaces were observed with a scanning electron microscope (SEM) and energy dispersive spectrometer (EDS).

\section{Experimental method}

\subsection{Samples}

The test ring samples were prepared by cutting commercial piston rings (top piston ring with a barrel profile) into small specimens. The piston ring was made of low-carbon steel P617 with a 0.01-mm-thick multi-layered $\mathrm{Cr}$ coating on the outer circle. The height 
of the piston ring and barrel profile were $1.2 \mathrm{~mm}$ and $2.0 \times 10^{-3} \mathrm{~mm}$, respectively. The cylinder liner sample was made of $70-\mathrm{mm}$ long, 35- $\mathrm{mm}$ wide, and 3- $\mathrm{mm}$ deep steel 45 . Figure 1 shows the structure of PRCL samples, and their material properties are presented in Table 1.

The lubricant was a high-performance semi-synthetic oil, i.e., SL10W-30. The key performance factors of this kind of oil include a density of $0.8627 \mathrm{~g} / \mathrm{cm}^{3}$, flash point of $218^{\circ} \mathrm{C}$ in an open environment, and a viscosity of $11.12 \mathrm{~mm}^{2} / \mathrm{s}$ at $100{ }^{\circ} \mathrm{C}$.

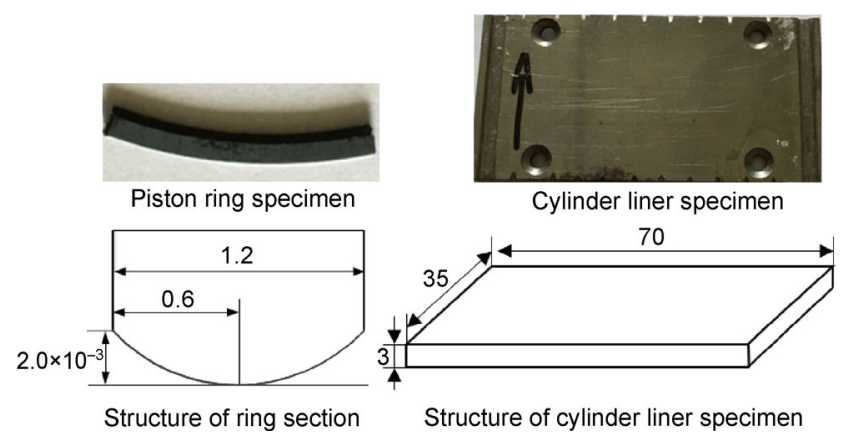

Fig. 1 Samples and structure of piston ring and cylinder liner.
The carbon nanotubes (model L-MWNT-2040) were supplied by the Shenzhen Nanotech Port Co. Ltd. These carbon nanotubes are synthesized by the catalytic chemical vapor deposition (CVD) process and possess excellent mechanical performance, superior electrical conductivity, and good thermal conductivity. The outer diameter of the CNTs was $20-40 \mathrm{~nm}$, the length was $5-15 \mu \mathrm{m}$, and the purity was over $97 \%$. The specific surface area was $90-120 \mathrm{~m}^{2} / \mathrm{g}$, the ash content was below $3 \mathrm{wt} \%$, and the tap density was $0.15-0.28 \mathrm{~g} / \mathrm{cm}^{3}$. These properties are summarized in Table 2.

\subsection{Experimental technique}

The experimental work was performed in the Key Laboratory of the Education Ministry for Modern Design and Rotor-Bearing Systems at Xi'an Jiaotong University. The tribological testing of the PRCL system was conducted using a multifunctional tribometer (e.g., pin-on-disc and reciprocating tribology tests), which was designed and developed by the third and first authors, as shown in Fig. 2(a). The friction coefficients were continuously recorded by the

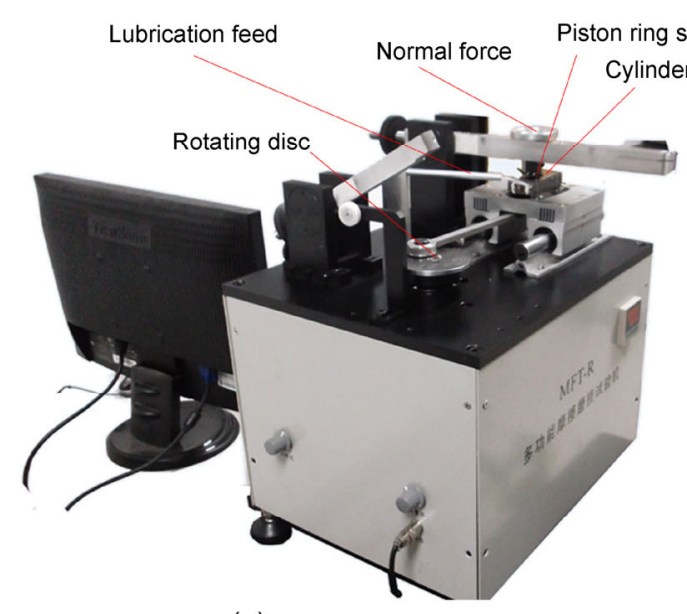

(a)

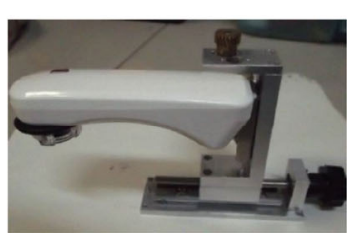

(b)

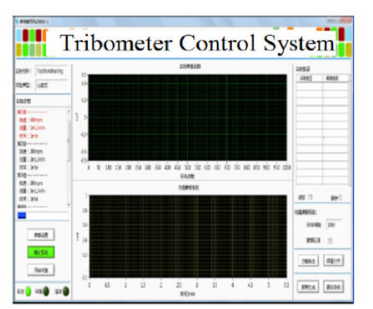

(c)

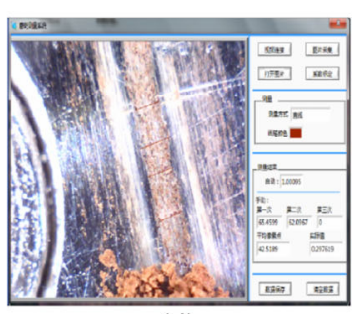

(d)

Fig. 2 Multi-functional tribometer. (a) Reciprocating tribometer test rig; (b) in-situ wear scar measurement and visualization system; (c) test control system; (d) online in-situ wear scar analysis.

Table 1 Material properties of piston ring and cylinder liner.

\begin{tabular}{ccccc}
\hline Samples & Material & Elasticity modulus & Hardness & Bending strength \\
\hline Piston ring & P617 & $\approx 186 \mathrm{Gpa}$ & $\geqslant \mathrm{HV} 400$ & $\geqslant 1470 \mathrm{MPa}$ \\
Cylinder liner & Steel 45 (C45) & $\approx 206 \mathrm{Gpa}$ & $\geqslant$ HRC55 & $\geqslant 355 \mathrm{MPa}$ \\
\hline
\end{tabular}

Table 2 Properties of carbon nanotubes.

\begin{tabular}{cccccc}
\hline Outer diameter & Length & Purity & SSA & ASH & Tap density \\
\hline $20-40 \mathrm{~nm}$ & $5-15 \mu \mathrm{m}$ & $>97 \%$ & $90-120 \mathrm{~m}^{2} / \mathrm{g}$ & $<3 \mathrm{wt}_{0}$ & $0.15-0.28 \mathrm{~g} / \mathrm{cm}^{3}$ \\
\hline
\end{tabular}


reciprocating tribometer, as shown in Fig. 2(c). The wear scars on the PRCL samples were measured and visualized using an in situ wear scar measurement system and visualization software, as shown in Figs. 2(b) and 2(d). The environmental conditions for the experiment were approximately $70 \%$ relative humidity and about $20{ }^{\circ} \mathrm{C}$ room temperature. Experimental parameters for the tribological testing are presented in Table 3.

Four types of tribological testing were conducted in this study: (1) dry friction without CNTs, (2) dry friction with CNTs, (3) lubricated conditions without CNTs, and (4) lubricated conditions with CNTs. All tests were performed at a speed of $100 \mathrm{rpm}$ under a constant load of $2 \mathrm{~N}$. Each test was performed for $45 \mathrm{~min}$ or more and repeated at least twice. Before and after testing, the samples were cleaned in acetone for $15 \mathrm{~min}$ and then dried in a drying chamber for $30 \mathrm{~min}$.

\subsection{Surface analysis}

Surface analysis of the worn area was conducted in order to study the wear mechanism. First, a moving digital microscope on a micro displacement table was used, and the focal length and amplification factor were set in advance with the help of a surveyor's rod. During the friction test, a camera was pointed at the wear scar via the micro displacement table, and the focus was adjusted. After taking a photograph, the image of the wear scar was imported into the analysis system. The computer software analyzed and calculated the width of the wear scar in real time. Accordingly, the wear data was stored and displayed. Second, an SEM (MERLIN COMPACT) and an EDS (OCTANE PLAS) were used to analyze the micrograph of the worn surfaces and the chemical element configuration, respectively.

Table 3 Tribological testing parameters.

\begin{tabular}{cc}
\hline Test specification & Value \\
\hline Load $(\mathrm{N})$ & 2 \\
Speed $(\mathrm{r} / \mathrm{min})$ & 100 \\
Frequency $(\mathrm{Hz})$ & 10 \\
Stroke $(\mathrm{mm})$ & 40 \\
Room temperature $\left({ }^{\circ} \mathrm{C}\right)$ & 20 \\
Oil temperature $\left({ }^{\circ} \mathrm{C}\right)$ & 100 \\
\hline
\end{tabular}

\section{Results and discussion}

\subsection{Friction}

Figure 3 shows the friction coefficients, with and without CNTs, under dry sliding conditions. It is clear that the friction coefficient value without CNTs is about 1 during the stable period, whereas that with CNTs is $0.1-0.2$. Comparison of the tribological testing results shows that the friction coefficient with CNTs is far less than that without CNTs. We conclude that during dry sliding tests, adding CNTs as a solid lubricant to the PRCL system can greatly decrease friction [26] because CNTs cover the contact surfaces and have sp2 bonding that generates a lower shear force and helps to reduce friction [15, 27]. Moreover, a decrease in the friction coefficient can reduce the heat generated during sliding. Owing to the outstanding thermal conductivity of CNTs, the thermal conductivity of the PRCL system is enhanced, and this helps to liberate the heat generated during the sliding process.

Figure 4 presents the friction coefficient with CNTs over a longer period of time. Before the test, we added some CNTs to the contact region. During the first $100 \mathrm{~min}$, the friction coefficient was low. From 100 to $127 \mathrm{~min}$, the friction coefficient greatly increased because of a reduction of CNTs in the motion trail. At the 127th minute, we added more CNTs to the motion trail. The friction coefficient then decreased over $127-145 \mathrm{~min}$. It can be concluded that the effective

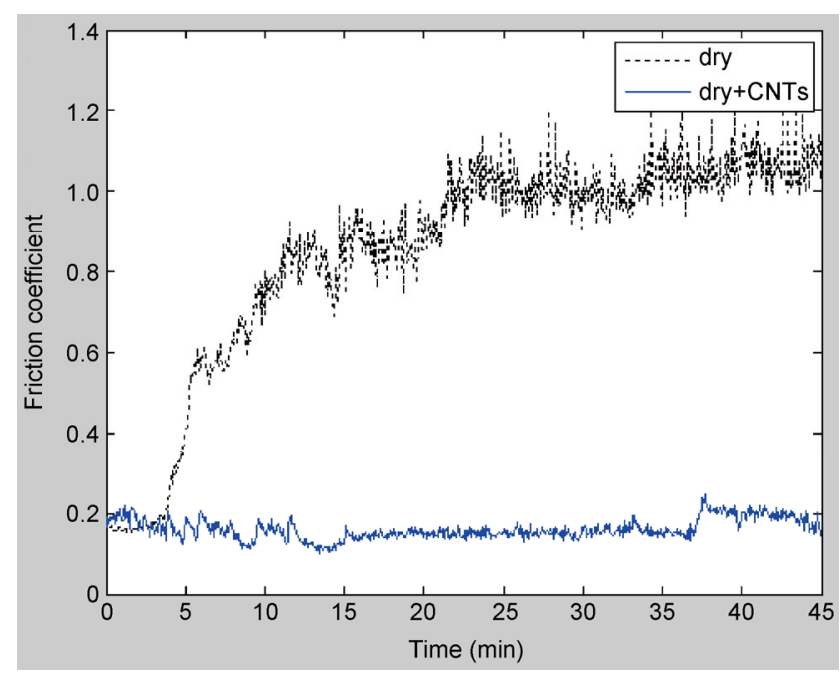

Fig. 3 Friction coefficients with or without CNTs under dry sliding condition. 


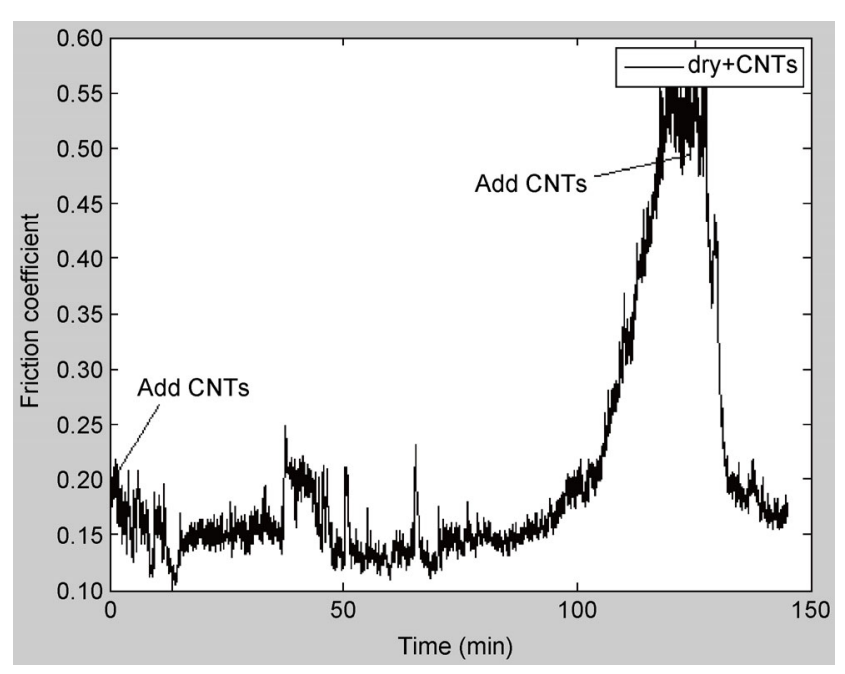

Fig. 4 Friction coefficient with CNTs in a long time.

time of CNTs is limited and the magnitude of the friction coefficient decreases with an increase in CNT content $[28,29]$.

Figure 5 presents the friction coefficients with and without CNTs under lubrication. It can be seen that the friction efficient increased slightly when CNTs were added to the lubricant. This may be because the CNTs act as grains in the lubricant, increasing abrasive wear and friction. Therefore, CNTs are not considered suitable as lubricant additives based on current investigation. However, further study is required to investigate whether CNTs can be used as lubricant additives in engines using bench test approach.

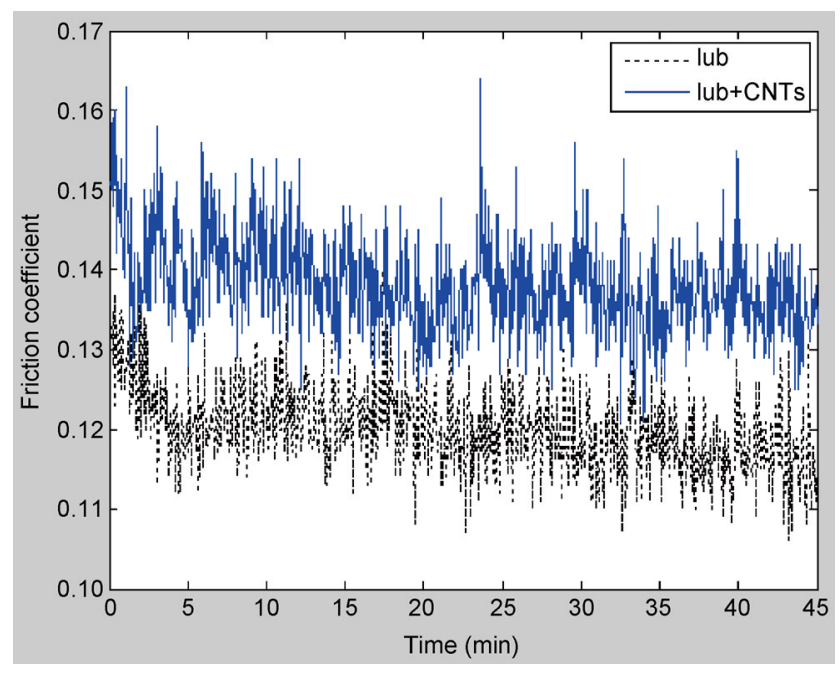

Fig. 5 Friction coefficient with or without CNTs under lubricated condition.

\subsection{Wear}

Figure 6 depicts the wear traces on the contact surfaces under dry sliding conditions. Figure 6(a) shows a wear trace, about $1 \mathrm{~mm}$ wide, on the cylinder liner without CNTs. Figure 6(b) shows a wear scar on the piston ring without CNTs, which is elliptic and dictated by the profile of the piston ring. The wear scar is not in the middle of the ring surface because the holder position was offset. Figure 6(c) shows a wear trace, about $0.6 \mathrm{~mm}$ wide, on the cylinder liner with CNTs. Figure 6(d) shows a wear scar on the piston ring with CNTs, which is obviously smaller than the one in Fig. 6(b).

It is evident that the width of the wear trace with CNTs under dry sliding conditions is smaller than that without CNTs. Hence, it can be concluded that adding CNTs to the PRCL system can result in wear reduction.

Under lubricated conditions, the wear trace is not obvious and cannot be measured directly. It is known from Fig. 5 that adding CNTs to the PRCL system under lubricated conditions slightly increases the friction coefficient. Also, it can be estimated that the difference between the wear traces under lubricated conditions with and without CNTs is small.

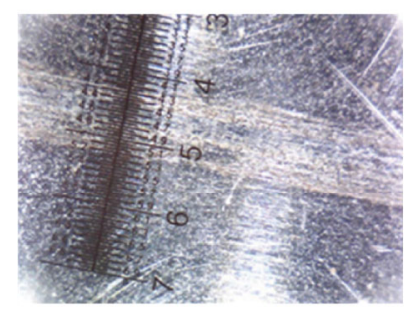

(a)

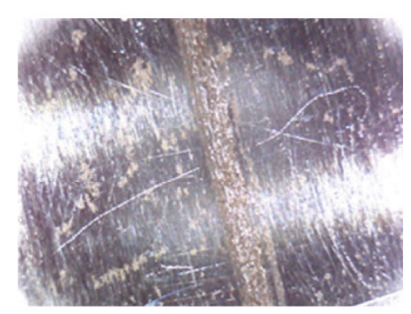

(c)

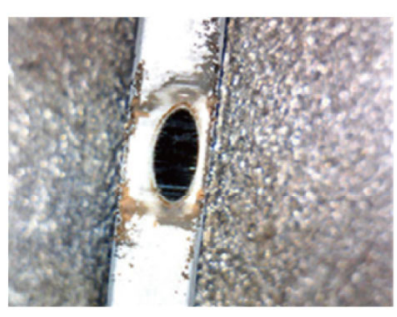

(b)

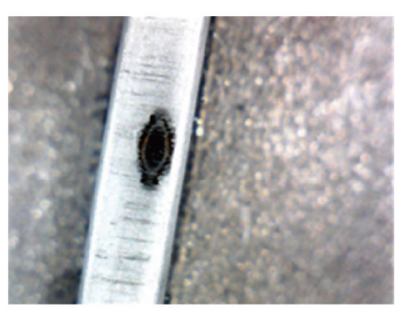

(d)
Fig. 6 Wear scar under dry sliding conditions. (a) Cylinder liner without CNTs; (b) piston ring without CNTs; (c) cylinder liner with CNTs; (d) piston ring with CNTs. 


\subsection{Surface analysis}

Surface analysis was conducted to investigate the wear mechanism under dry sliding condition with CNTs, and the contact surfaces were observed with an SEM and EDS. Figure 7 shows the SEM images of the piston ring with CNTs under dry sliding conditions. Figures 7(a) and 7(b) show the ring surface before and after testing, respectively. Before the test, the ring surface was homogenous, while after the test, a large wear scar was observed on the contact surface. It can be seen that a carbon film formed on the surface. The elements in the contact region after the test are shown in Fig. 8. The elements were $\mathrm{C}, \mathrm{O}, \mathrm{Fe}$, and $\mathrm{Cr}$, where: $\mathrm{Fe}$ is the substrate of the piston ring; $\mathrm{Cr}$ is the coating on the ring surface; $\mathrm{O}$ comes from the oxide layer; and $\mathrm{C}$ comes from the CNTs. It can be deduced that the CNTs covered the contact surface and protected it from friction and wear. The special tubular structure, high strength, and high toughness of CNTs can significantly improve the anti-friction and wear resistance of the metal matrix [24].

Figure 9 presents the wear trace of the cylinder liner with CNTs under dry sliding conditions. Figure 9(a) is the SEM image and Fig. 9(b) is the EDS spectrum. It is clear from Fig.9(a) that the dominant wear mechanism is adhesive wear [20]. As can be seen in Fig. 9(b), the elements in the contact region are $\mathrm{C}, \mathrm{O}$, and $\mathrm{Fe} ; \mathrm{Fe}$ is the substrate, $\mathrm{O}$ comes from the oxide layer, and C comes from the CNTs. It is confirmed that the CNTs adhered to the contact surface of the cylinder liner and formed a protective layer. Because of the low shear characteristics of CNTs, the friction coefficient is smaller than without CNTs.

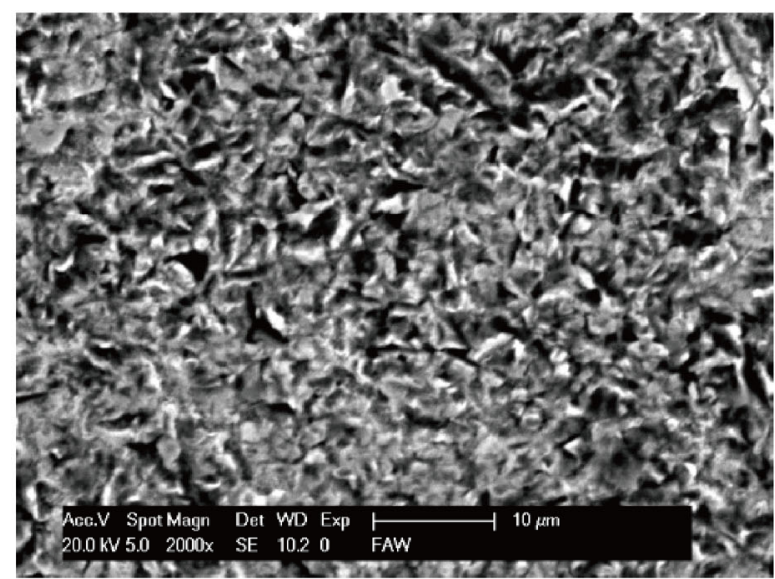

(a)

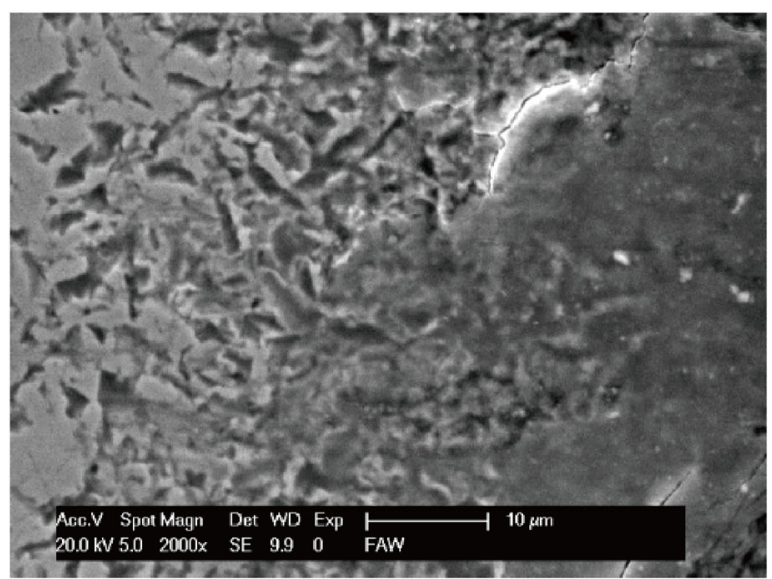

(b)

Fig. 7 SEM images of the piston ring under dry sliding conditions with CNTs: (a) before the tribological testing, and (b) after the tribological testing.

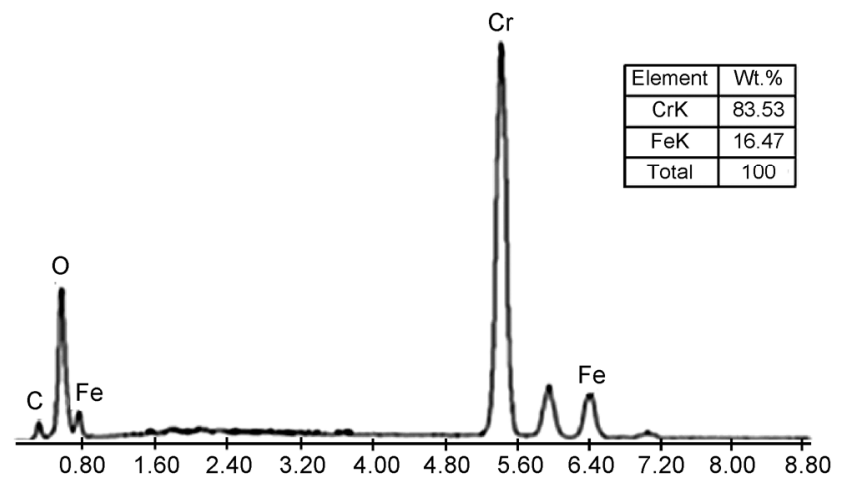

Fig. 8 EDS spectrum of the ring surface after the test. 


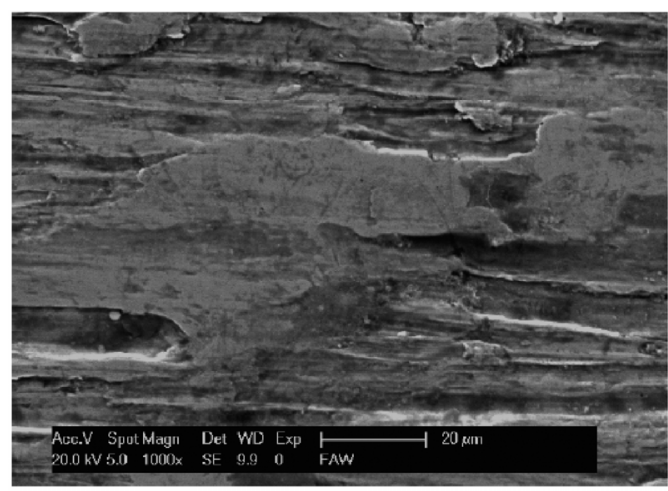

(a)

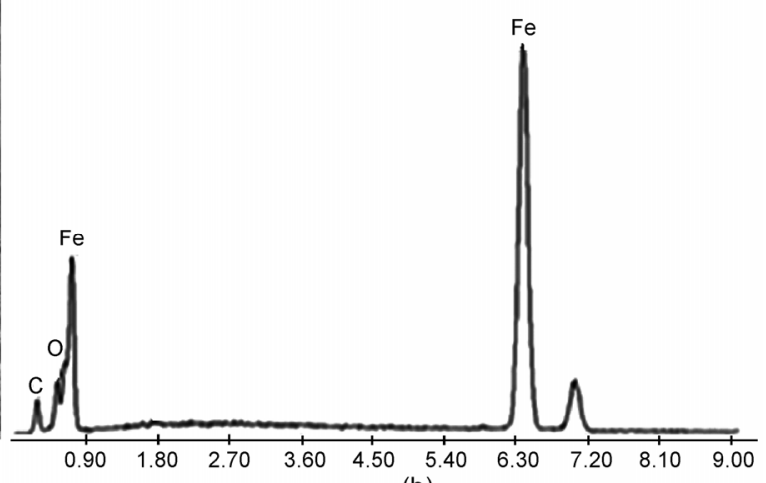

(b)

Fig. 9 Wear trace of the cylinder liner under dry sliding conditions with CNTs. (a) SEM image, and (b) EDS spectrum.

\section{Conclusions}

This study investigated the effects of carbon nanotubes on the tribological performance of a PRCL system under dry and lubricated conditions. Under dry friction, the CNTs act as a solid lubricant, and under lubricated conditions, it can be regarded as a kind of additive to the lubricant. Under dry sliding conditions, adding CNTs to a PRCL system can result in a large reduction in friction and wear. Based on SEM and EDS analysis, it was found that CNTs formed a carbon film covering the contact surfaces. Because of the low shear property of CNTs, the friction coefficient decreased compared to those samples without CNTs. Under dry friction, the effective time of CNTs is limited, and the friction coefficient decreases with an increase in CNT content. The wear mechanism under dry friction is mainly adhesive wear. Under lubricated conditions, adding CNTs to the lubricant slightly increases the friction coefficient.

\section{Acknowledgments}

The research presented in this paper was partially funded by the National Natural Science Foundation of China (Nos. 51575340 and 51575342) and Research Project of State Key Laboratory of Mechanical System and Vibration (No. MSVZD201104).

Open Access: The articles published in this journal are distributed under the terms of the Creative
Commons Attribution 4.0 International License (http:// creativecommons.org/licenses/by/4.0/), which permits unrestricted use, distribution, and reproduction in any medium, provided you give appropriate credit to the original author(s) and the source, provide a link to the Creative Commons license, and indicate if changes were made.

\section{Reference}

[1] Holmberg K, Andersson P, Erdemir A. Global energy consumption due to friction in passenger cars. Tribol Int 47: 221-234 (2012)

[2] Tung S, McMillan M L. Automotive tribology overview of current advances and challenges for the future. Tribol Int 37(7): 517-536 (2004)

[3] Wong V W, Tung S. Overview of automotive engine friction and reduction trends-Effects of surface, material and lubricantadditive technologies. Friction 4(1): 1-28 (2016)

[4] Etsion I, Sher, E. Improving fuel efficiency with laser surface textured piston rings. Tribol Int 42(4): 542-547 (2009)

[5] Skopp A, Kelling N, Woydt M, Berger L M. Thermally sprayed titanium suboxide coatings for piston ring/cylinder liners under mixed lubrication and dry-running conditions. Wear 262(9-10): 1061-1070 (2007)

[6] Meng F M, Wang J X, Xiao K. A study of the influences of particles in the gas flow passage of a piston ring pack on the tribological performances of the piston ring. Proc IMechE, Part C: J Mech Eng Sci 224(1): 201-215 (2010)

[7] Smith E H. Optimising the design of a piston-ring pack using DoE methods. Tribol Int 44: 29-41 (2011) 
[8] Iijima S. Helical microtubules of graphitic carbon. Nature 354(6348): 56-58 (1991)

[9] Ajayan P M. Nanotubes from carbon. Chem Rev 99(99): 1787-1800 (1999)

[10] Suhr J, Koratkar N, Keblinski P, Ajayan P. Viscoelasticity in carbon nanotube composites. Nat Mater 4(2): 134-137 (2005)

[11] Tu J P, Yang Y Z, Wang L Y, Ma X C, Zhang X B. Tribological properties of carbon-nanotube-reinforced copper composites. Tribol Lett 10(4): 225-228 (2001)

[12] Ulus H, Üstün T, Eskizeybek V, Ömer Sinan Şahin Avcı A, Ekrem M. Boron nitride-mwent/epoxy hybrid nanocomposites: Preparation and mechanical properties. Appl Surf Sci 318: 37-42 (2014)

[13] Treacy M M J, Ebbesen T W, Gibson J M. Exceptionally high young's modulus observed for individual carbon nanotubes. Nature 381(6584): 678-680 (1996)

[14] Yan L, Wang H, Wang C, Sun L, Liu D, Zhu Y. Friction and wear properties of aligned carbon nanotubes reinforced epoxy composites under water lubricated condition. Wear 308(308): 105-112 (2013)

[15] Düzcükoğlu H, Ekinci Ş, Şahin Ö S, Avci A, Ekrem M, Ünaldi M. Enhancement of wear and friction characteristics of epoxy resin by multiwalled carbon nanotube and boron nitride nanoparticles. Tribol Trans 58(4): 635-642 (2015)

[16] Cui L J, Geng H Z, Wang W Y, Chen L T, Gao J. Functionalization of multi-wall carbon nanotubes to reduce the coefficient of the friction and improve the wear resistance of multi-wall carbon nanotube/epoxy composites. Carbon 54(4): 277-282 (2013)

[17] LaBarre E D, Calderon-Colon X, Morris M, Tiffany J, Wetzel E, Merkle A, TrexLer M. Effect of a carbon nanotube coating on friction and impact performance of kevlar. J Mater Sci 50(16): 5431-5442 (2015)

[18] Gandhi R A, Palanikumar K, Ragunath B K, Davim J P. Role of carbon nanotubes (cnts) in improving wear properties of polypropylene (pp) in dry sliding condition. Mater Design

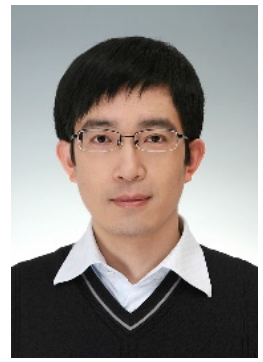

Zhinan ZHANG. He received his Ph.D. degree in 2011 from Shanghai Jiao Tong University, Shanghai, China. After that he was a post doctor in Shanghai Jiao Tong University. He is now working as an assistant
48(2): 52-57 (2012)

[19] Lee S M, Shin M W, Jang H. Effect of carbon-nanotube length on friction and wear of polyamide 6,6 nanocomposites. Wear 320(s1-2): 103-110 (2014)

[20] Al-Qutub A M, Khalil A, Saheb N, Hakeem A S. Wear and friction behavior of Al6061 alloy reinforced with carbon nanotubes. Wear 297(s1-2): 752-761 (2013)

[21] Bastwros M M H, Esawi A M K, Wifi A. Friction and wear behavior of Al-CNT composites. Wear 307(1-2): 164-173 (2013)

[22] Abdullahi U, Maleque M A, Nirmal U. Wear mechanisms map of CNT-Al nano-composite. Procedia Eng 68(12): 736-742 (2013)

[23] Khun N W, Troconis B C R, Frankel G S. Effects of carbon nanotube content on adhesion strength and wear and corrosion resistance of epoxy composite coatings on aa2024-t3. Prog Organic Coat 77(1): 72-80 (2014)

[24] Liu H, Ji H, Hong H, Younes H. Tribological properties of carbon nanotube grease. Ind Lubr Tribol 6(5): 2-2 (2014)

[25] Kałużny J, Iskra A, Babiak M, Krzymień P, Giersig M, Kempa K. Selected applications of carbon nanotubes in construction of internal combustion engine. J Peripheral Nervous System 18(2): 192-194 (2014)

[26] Jacobs O, Xu W, Schädel B, Wu W. Wear behaviour of carbon nanotube reinforced epoxy resin composites. Tribol Lett 23(23): 65-75 (2006)

[27] Bastwros M M H, Esawi A M K, Wifi A. Friction and wear behavior of Al-CNT composites. Wear 307(1-2): 164-173 (2013)

[28] Zoo Y S, An J W, Lim D P, Lim D S. Effect of carbon nanotube addition on tribological behavior of uhmwpe. Tribol Lett 252(5-6): 512-517 (2002)

[29] Choi H J, Lee S M, Bae D H. Wear characteristic of aluminum-based composites containing multi-walled carbon nanotubes. Wear 270(1): 12-18 (2010)

researcher in the School of Mechanical Engineering, Shanghai Jiao Tong University. His research interests include computational design and analysis of tribosystems, and theory and methods of design engineering and innovation. 